\title{
Formação continuada de professores de ciências utilizando a Aquaponia como ferramenta didática
}

\author{
Science teachers' continuing training \\ using Aquaponics as a didactic tool
}

\author{
Rondon Tatsuta Yamane Baptista de Souza ${ }^{1}$ \\ https://orcid.org/0000-0002-5459-6167 \\ Leandro de Oliveira Souza ${ }^{2}$ \\ https://orcid.org/0000-0003-1626-0766?lang=en \\ Sarah Ragonha de Oliveira ${ }^{1}$ \\ https://orcid.org/0000-0003-4319-3925 \\ Erico Luis Hoshiba Takahashi ${ }^{3}$ \\ https://orcid.org/0000-0002-6833-4440
}

\begin{abstract}
Resumo: Este estudo relata uma pesquisa de mestrado que teve como foco desenvolver a formação de professores de ensino médio, procurando compreender como a Aquaponia pode dar suporte para atividades pedagógicas, enfatizando o desenvolvimento da ciência. Os resultados retratam a dificuldade de aplicar a interdisciplinaridade com projetos integrados na escola, devido à extensa carga horária de trabalho dos professores e ementas com conteúdos amplos, o que acarreta falta de tempo para planejar e realizar atividades em conjunto. Isso repercute na falta de interesse e na indisciplina dos alunos. Contudo, as avaliações finais dos professores que utilizaram o sistema foram positivas: eles ressaltaram a importância de atividades que fogem do cotidiano da sala de aula, pois as aulas diversificadas prendem a atenção dos alunos e os motivam a interagir com os professores.
\end{abstract}

Palavras-chave: Formação continuada do professor. Ensino médio. Ensino por projetos. Aquaponia.

\begin{abstract}
This study reports on a study that focused on the continuing education of secondary school teachers, trying to understand how aquaponics could support pedagogical activities, emphasizing the development of science. Results show the difficulty in applying interdisciplinarity to integrated projects at school, due to the heavy workload for teachers, and contents that they should account for, which leads to a lack of time to plan and carry out activities together. This may have an effect on students' lack of interest and indiscipline. However, teachers' final evaluations using the system were positive, thus reflecting the importance of activities that differ from everyday classroom routines. We realize that these diverse classes hold students' attention and motivate them to interact with teachers.
\end{abstract}

Keywords: Continuing teacher training. Secondary school. Self-guided projects. Aquaponics.

\footnotetext{
${ }^{1}$ Instituto Federal de Educação, Ciência e Tecnologia do Amazonas (IFAM), Itacoatiara, AM, Brasil. E-mail: rondon.souza@ifam.edu.br

${ }^{2}$ Universidade Federal de Uberlândia (UFU), Ituiutaba, MG, Brasil.

${ }^{3}$ Universidade Federal do Amazonas (UFAM), Instituto de Ciências Exatas e Tecnologia, Itacoatiara, AM, Brasil.
} 


\section{Introdução}

O presente estudo relata uma pesquisa de mestrado realizada na Universidade Federal do Amazonas (UFAM), que utilizou um sistema de aquaponia como subsídio para atividades teóricas e práticas das aulas de professores de ensino médio em uma escola estadual no município de Itacoatiara, AM. O projeto foi financiado pela fundação $\mathrm{ELAS}^{4}$ e, por meio da implantação, nas dependências da escola, de um sistema conhecido por Aquaponia, que integra aquicultura e hidroponia, objetivou empoderar mulheres e desmistificar ideias de que meninas não aprendem ciências e matemática com a mesma propriedade que meninos.

O termo aquaponia é recente, porém os povos tradicionais Aztecas já utilizavam um sistema de produção com esses mesmos conceitos desde os anos de 1400: a aquaponia é um sistema de produção integrado, que pode ser utilizado para produção de peixes e hortaliças em um mesmo ambiente, e tem sido empregado como laboratório em situações em que os professores ministram suas aulas de forma interdisciplinar e fora do microambiente de sala de aula, como forma de tornar as aulas mais atrativas e interessantes aos alunos.

Neste artigo relataremos parte do projeto, que teve por foco desenvolver a formação de professores de ensino médio nas disciplinas de química, física, biologia e matemática. Procuramos compreender como o uso de um sistema integrado de produção de alimentos poderia dar suporte para atividades pedagógicas, com foco no desenvolvimento da ciência. Ao mesmo tempo, estudantes (mulheres) do Programa Institucional de Bolsas de Iniciação à Docência (PIBID) de Biologia da Universidade Federal do Amazonas foram envolvidas, com o objetivo de potencializar a formação inicial de professores. O potencial pedagógico do sistema e os impactos na prática docente são objetos de análise.

A pesquisa foi desenvolvida entre os meses de março e novembro de 2016. O projeto foi planejado e proposto pelos pesquisadores e executado pelo primeiro autor deste texto. Professores do ensino médio de uma escola estadual do município de Itacoatiara, AM, foram convidados a participar de todas as etapas. Ao todo, dez professores das disciplinas de ciências e matemática se voluntariaram a participar das atividades. Os dados resultaram de audiogravação dos diálogos durante a formação e de imagens videogravadas. Para fins da pesquisa, os professores foram convidados a elaborar um plano de aula para ser ministrada, o qual deveria conter os assuntos referentes às disciplinas e às turmas para que lecionavam. Esses planos também compõem o rol de dados analisados. Após a entrega, nos reunimos com os professores, com o intuito de discutir os planos e traçar as estratégias para realização das aulas. A análise dos dados coletados deu-se de forma interpretativa, de modo que procuramos compreender qual o potencial do sistema para a formação de professores durante a ação de planejamento pedagógico de aulas interdisciplinares.

\footnotetext{
${ }^{4}$ Lançado em 2000, o Fundo de Investimento Social ELAS é independente e tem se dedicado a promover e fortalecer o protagonismo, a liderança e o direito das mulheres. Mais informação disponível em: http://www. fundosocialelas.org
} 


\section{Formação continuada de professores e algumas causas de desmotivação profissional}

Um dos principais alicerces da formação continuada para professores consiste em uma abordagem que vise aumentar a autoestima docente. É necessário envolvê-los de forma que possam perceber que é possível se redescobrir como educador e reconhecer que o conhecimento e o aprendizado constituem uma via de mão dupla. Porém, para que os professores tenham interesse em formações, se faz necessário apresentar-lhes propostas inovadoras e criativas, que contemplem seus anseios. Formações docentes costumam ter como foco principal demandas pedagógicas, porém não fazem relações com as disciplinas ensinadas na escola. Torna-se necessário envolver os professores em atividades de planejamento coletivo, de forma que os discursos possam estimular o aprendizado de práticas pedagógicas atreladas ao objeto de estudo das disciplinas que lecionam.

Carvalho e Gil-Pérez (1993) afirmam que cabe ao professor questionar as visões de ciência que determinam abordagens na escola de maneira repetitiva, dogmática e acrítica, e buscar experiências exitosas com o ensino de ciências, que se iniciam a partir do senso comum. A nossa abordagem de pesquisa foi pautada nas dificuldades que os professores de escolas públicas no estado do Amazonas atravessam ao "tentar" realizar atividades diferenciadas, aulas práticas e experimentos no âmbito da escola.

Empecilhos relacionados à sobrecarga de trabalho desestimulam a participação em formações e o desenvolvimento de atividades extracurriculares. Lapo e Bueno (2003) relatam que baixos salários, relações interpessoais no ambiente de trabalho e, principalmente, falta de gestão democrática são também motivos que geram a desmotivação docente. Nóvoa (1991) entende que a "vocação pedagógica" foi associada durante muito tempo a uma "vocação sacerdotal" e, por esse motivo, é uma missão usualmente mal remunerada e pouco valorizada pelo poder público. Nesse contexto nos questionamos: como provocar professores para participar de projetos extraclasse e formações em seus horários de planejamento e quais seriam os resultados?

A primeira hipótese que levantamos é que a formação inicial dos professores poderá não ter sido tão eficaz. Acreditamos que existam lacunas de ordem teórica e prático-pedagógica que devem ser preenchidas com espaços formativos. Outro ponto que acreditamos ser relevante é que os professores deveriam passar constantemente por momentos de formação continuada, revendo seu papel de educador, com o objetivo de melhorar a formação cidadã, ommilateral, sustentável e cultural.

Nos trabalhos de Bolam e McMahon (2004) e Terigi (2010), a definição de formação continuada é ainda mais ampla: os autores fazem referência a outras noções, como formação permanente, formação contínua, formação em serviço, desenvolvimento de recursos humanos, aprendizagem ao longo da vida, cursos de formação continuada e discussões sobre educação e avaliação.

O professor deveria, por força do ofício, manter-se atualizado com os avanços tecnológicos e os temas contemporâneos, uma vez que prepara os educandos para a vida, e não só para realizar provas e atividades escolares. Sendo assim, é preciso promover espaços para formação continuada que deem suporte para a atuação desses profissionais (SOUZA; MANCINI, 2002; TEIXEIRA, 2001). 
Para Menezes (1996), a formação de um professor, independentemente de onde e como se processe, se faz a longo prazo e não se encerra ao fim de sua licenciatura. Isso ocorre porque a formação docente é um processo complexo, para o qual são necessários muitos conhecimentos e habilidades, nem todos adquiridos no curto espaço de tempo que dura a formação inicial. A cada dia surgem novos problemas, dúvidas e questionamentos que demandam professores preparados e atualizados.

Segundo Shulman (1987), os docentes detêm um conhecimento específico e, portanto, são protagonistas de uma construção que o autor denomina o conhecimento pedagógico do conteúdo, o qual se deve articular e não se justapor; ou seja, não se separa forma e conteúdo. Assim, quando Shulman descreveu o PCK, sigla em inglês para Pedagogical Content Knowledge, ele tinha a intenção clara de demonstrar aos leitores a capacidade de um professor apresentar determinados conteúdos levando em consideração as experiências e bagagens dos alunos (SHULMAN, 1987).

Esse conhecimento específico não faz do professor um professor, e sim o coloca como um especialista de algo conhecido por ele. Quando empregamos a palavra professor, temos em vista uma pessoa que, além dos conhecimentos específicos das imensas listas de conteúdos obrigatórios, possa também relacionar esses assuntos com as demandas, os anseios e as necessidades dos educandos. Assim, o professor deve conhecer os conteúdos, mas ainda ser capaz de conectá-los com os conhecimentos prévios, descritos por Ausubel (2003) como subsunçores. Dessa maneira, os alunos terão ciência de que os assuntos abordados em sala de aula são conceitos conhecidos e importantes para a sua formação.

De certa forma, é essencial que os docentes tenham a possibilidade de formação permanente, diversificada e de qualidade; que a formação continuada investigue coletivamente os problemas de ensino-aprendizagem encontrados durante o exercício da profissão. É importante salientar que não são todas as escolas que propiciam momentos de interação e diálogo entre os professores. Existem poucas oportunidades de discussão e reflexões em grupo. Atividades coletivas com foco na aprendizagem e no planejamento de aulas poderiam solucionar os problemas de comunicação e também auxiliar a pensar atividades interdisciplinares e projetos escolares voltados para o ensino, a pesquisa e a extensão escolar.

Uma característica do ensino no Brasil é que a carga horária em sala de um professor com contrato de 40 horas em uma escola estadual é de 32 horas, e lhe restariam 8 horas para planejar e preparar aulas, corrigir trabalhos e provas, preencher diários, participar de outras atividades, além da sua própria formação. $\mathrm{Na}$ escola que abrigou o trabalho aqui apresentado, os professores têm entre 12 e 16 turmas diferentes para trabalhar no decorrer da semana. A pergunta que se coloca é: como encorajar professores para participar de atividades de formação extraclasse com foco na discussão interdisciplinar? Nossa experiência nos permite sugerir propostas, que passamos a expor.

\section{Uso de projetos na Educação}

A utilização de projetos na educação tem por objetivo fazer as disciplinas conversarem entre si, trazer à tona práticas pedagógicas diversificadas e importantes para o contexto social dos estudantes, tirar as disciplinas da inércia, de forma que passem a integrar um currículo diferenciado, proporcionando uma formação global. 
O uso de projetos, especialmente os inovadores, estimula o educando a procurar soluções para problemas no decorrer do processo. Essa busca leva os alunos a pesquisar, discutir e propor medidas para elucidar esses dilemas. Grant e Hill (2006) discutem fatores influentes que desempenham um papel em uma pedagogia centrada no aluno e explicam que os professores devem ser capazes de reconhecer e aceitar mudanças em suas funções e de sentir-se à vontade com a implementação de novas metodologias pedagógicas. Devem, de forma gradativa, ir migrando para uma maneira diferenciada e construtivista de educação - centrada no aluno e não apenas no conteúdo.

A aprendizagem baseada em projetos é um modelo de instrução que se baseia na abordagem construtivista de aprendizagem: implica a construção de conhecimento com múltiplas perspectivas, dentro de uma atividade social, e permite a autoconsciência de aprender e conhecer (DUFFY; CUNNINGHAM, 1996).

Atualmente, muitos currículos são organizados de forma estritamente conteudista, voltados à preparação para provas, vestibulares e concursos. Essa visão nos parece ser pouco eficiente para acolher as demandas e os problemas da sociedade contemporânea. Hertzog (2007) afirma que, ao trabalhar com projetos, os professores sentem dificuldades de acompanhar o currículo exigido e, além disso, receiam perder o controle sobre os conteúdos e o seu papel ativo em relação a eles. Portanto, nem sempre os professores serão adeptos dessas mudanças.

O fato de o trabalho com projetos preconizar uma abordagem construtivista no processo de ensino e aprendizagem exige experiência em atividades socializadoras, além da concepção de que os assuntos serão compreendidos, e não apenas supostamente aprendidos. Além disso, é necessário considerar o envolvimento com os alunos, principalmente por eles trabalharem em grupo e em grupo tomarem suas decisões. Por um lado, o fato de os alunos trabalharem em grupos poderia ser o aspecto mais difícil ao lecionar conceitos por projetos (KAPP, 2009). Por outro, Kolodner et al. (2003) entendem que a criação de uma cultura de colaboração em sala de aula faz com que os alunos se sintam corresponsáveis por ajudar-se mutuamente e, nessa interação, quando erram, aprendem com os erros, o que torna o processo benéfico.

A esse respeito, Meyer, Turner e Spencer (1997) enfatizaram a importância de criar um ambiente de sala de aula que suporte o domínio e desenvolva uma visão construtiva do erro. Ao cometer erros, os alunos podem sentir-se fracassados, porém a aprendizagem por projetos poderia estimular uma preocupação maior de examinar as falhas dos alunos do que de valorizar o sucesso. Assim, trabalhando em colaboração, os alunos iriam experimentar ideias com seus colegas de classe e aprender com os erros. A colaboração é um aspecto importante na educação por projetos, e os professores precisam assegurar que o processo resulte em uma experiência positiva e gratificante, que melhore a aprendizagem e o desempenho dos alunos.

Atividades que fogem do comum, chamadas anteriormente de diferenciadas, podem dar suporte aos professores no momento em que precisam explicar seus conteúdos. Elas subsidiam o profissional a mostrar na prática o porquê de ensinar determinados assuntos. A utilização de projetos e atividades extraclasse poderia trazer a realidade e o contexto sociocultural dos estudantes para dentro da sala de aula.

Pensando por esse prisma, Williams e Dixon (2013) citam a jardinagem como atividade agrícola nas escolas, apontando que esse tipo de aprendizagem se alinha com duas 
tendências recentes de interesse público: o crescimento da consciência para a melhora da saúde, particularmente das crianças; a oportunidade de os alunos passarem mais tempo na natureza. O aprendizado experimental através da jardinagem tem uma ampla variedade de impactos na aprendizagem: inclui melhora no desempenho em ciências, matemática e artes, além de resultados não acadêmicos, como aumento da preferência por frutas e vegetais, desenvolvimento pessoal, cooperação e consciência ambiental (PARMER et al., 2009; WILLIAMS; DIXON, 2013).

Outro exemplo de atividade agrária que vem sendo utilizada na educação é a aquaponia. Hart, Webb e Danylchuk (2013), baseados no número de escolas nos Estados Unidos, Europa e Ásia utilizando sistemas aquapônicos, além da incidência crescente de buscas na internet e em artigos que abordam o tema, apontam que o uso da aquaponia na educação parece estar atraindo a atenção dos educadores. Esse interesse se deve à interação entre a educação científica e o funcionamento em si do sistema (HART; WEBB; DANYLCHUK, 2013), uma vez que o funcionamento da aquaponia incorpora o conhecimento de uma variedade de assuntos, incluindo agricultura, biologia, engenharia, nutrição, química e tecnologia (GENELLO et al., 2015). Também os estudos de Wardlow et al. (2002) preconizam essas características do uso da aquaponia e afirmam que, em razão da tecnologia envolvida, esse sistema oferece aos educadores a oportunidade de reunir esses conhecimentos de maneira interdisciplinar nos seus planos de aula e poderá ser empregado em escolas públicas para subsidiar a aplicação de aulas práticas para diversas disciplinas. Neste artigo, enfatizaremos o acompanhamento das disciplinas de biologia, química, matemática e física.

No interior da região amazônica, o cotidiano de vida dos alunos está diretamente ligado ao contexto do projeto, em que as famílias produzem parte de seus alimentos e ainda têm uma íntima ligação com a água e os peixes.

O consumo per capita de pescado por ano, por exemplo, na região Norte do Brasil é muito acima da média nacional, que gira em torno de apenas $10 \mathrm{~kg} /$ ano (ANUÁRIO BRASILEIRO DA PESCA E AQUICULTURA, 2014). Santos (2004) menciona um consumo de até $500 \mathrm{~g}$ de peixe por dia e a comercialização de $40 \%$ da pesca realizada no rio Solimões/ Amazonas, sendo $60 \%$ da captura direcionada à subsistência. Esse fato torna a produção de pescado muito importante, uma vez que os estoques naturais estão cada vez mais escassos. Em contrapartida, o consumo de hortaliças é baixo, em relação às outras regiões do País, o que se deve ao fato de o hábito alimentar da população não incluir esses alimentos em sua dieta. Porém, cada vez mais a população das cidades procura por alimentos saudáveis e frescos, o que torna a produção de hortaliças uma atividade em expansão, com grande potencial para ser produzida em sistemas integrados como a aquaponia. Parece-nos também que o projeto, além produzir pescados e hortaliças de forma sustentável e a baixo custo, ainda poderá despertar nos envolvidos um espírito empreendedor e, em um futuro próximo, transformar a vida das pessoas.

Tomando como bases essas considerações e pensando em minimizar as dificuldades anteriormente enfrentadas na escola e tornar possível a utilização de ferramentas didáticas pelos professores, propusemos um projeto que une experiências de outros pesquisadores à aquaponia, inserida no contexto escolar, compondo uma espécie de laboratório, principalmente para as disciplinas de física, matemática, química e biologia. 


\section{Metodologia}

Neste artigo optamos por uma abordagem de natureza metodológica qualitativa: as falas obtidas durante as entrevistas e os diálogos foram transcritas, e as enunciações serão aqui relatadas. Fizemos opção por esta metodologia por ser um processo indutivo que visa compreender os fenômenos de maneira multidimensional e descreveremos detalhadamente cada passo da pesquisa, objetivando o entendimento dos processos envolvidos, as características dos atores e os resultados obtidos durante a pesquisa.

O local escolhido para a realização deste trabalho foi uma escola estadual de nível médio, que funciona em dois turnos, matutino e vespertino, com aproximadamente 890 alunos, divididos em 27 turmas de primeiro, segundo e terceiro anos do ensino médio, provenientes dos bairros periféricos à sede do município e da zona rural. A escola não dispõe de laboratórios de ciências e matemática, e esse foi um dos motivos pelos quais escolhemos implantar ali o projeto. Outra razão relevante dessa escolha foi a presença dos alunos do Programa de Iniciação à Docência (PIBID), ligados à Universidade Federal do Amazonas: já estávamos realizando com eles um projeto macro, anteriormente aprovado e financiado pela Fundação Carlos Chagas, ligada à Fundação Unibanco, que previa a implantação de um sistema aquapônico que seria utilizado em aulas práticas com os alunos do ensino médio. Buscávamos também avaliar os efeitos do uso de projetos sobre o processo de ensino-aprendizagem e proporcionar o empoderamento feminino nas disciplinas das ciências exatas e naturais.

Participaram da pesquisa os professores de matemática, química, física e biologia, efetivos e contratados, com cargas horárias variando de 20 a 40 horas semanais, todos com licenciatura nas áreas específicas e alguns deles com mestrado ou pós-graduação na área.

A proposta deste trabalho foi apresentada aos professores no início do ano letivo de 2016, quando recebemos a confirmação de que nosso projeto havia sido aprovado e seu recurso já estaria liberado. Para gerar dados para as análises e implementar as atividades previstas na pesquisa, as atividades foram divididas por fases.

Na primeira fase, chamada de sensibilização, os professores foram divididos por eixos: 1 (matemática e física) e 2 (química e biologia), de acordo com o horário previsto para planejamento de atividades dos professores na escola. Foram realizadas quatro reuniões no início do ano letivo de 2016, duas no período da manhã e duas no período da tarde, ambas com os professores dos eixos 1 e 2 . Essa divisão foi realizada para atender os horários disponíveis dos professores, visto que parte deles só permanecia na escola em um dos períodos.

Nesta fase apresentamos os conceitos de aquaponia; mostramos a eles como um sistema funciona, as diferentes formas em que ele pode se apresentar, os usos da aquaponia pelo mundo e alguns resultados de pesquisas realizadas com a utilização do sistema; e discutimos com os professores de cada área onde a aquaponia poderia se inserir para contribuir na formação dos alunos do ensino médio.

Após a apresentação, os professores tiveram a oportunidade de discutir sobre o tema com o pesquisador, tirar dúvidas e propor ideias para a realização desse projeto (Figura 1). Ao fim da reunião, propusemos que cada um fizesse um plano de ação para utilizar o sistema de aquaponia em sua disciplina. Combinamos o prazo de 15 dias para que os planos fossem produzidos. 
Figura 1 - Reunião de apresentação da proposta aos professores ${ }^{5}$

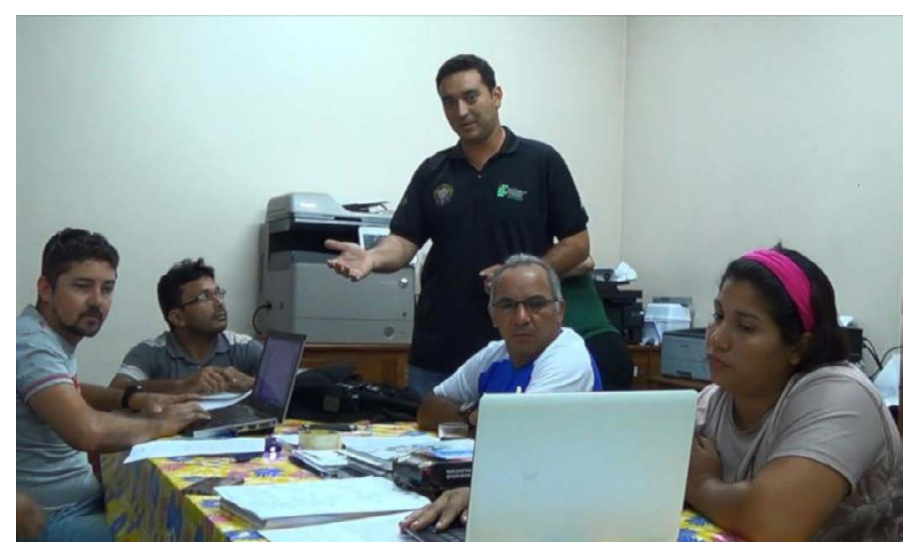

Fonte: Arquivo dos autores.

Ao fim desse prazo, apenas dois professores entregaram a proposta. Como estávamos no início do ano letivo, e muitas atividades de planejamento foram elencadas por eles como prioritárias, um novo prazo foi estipulado em comum acordo com os professores: prolongamos por mais 15 dias a data de entrega. Nove dos dez professores convidados entregaram as suas propostas, e iniciamos as discussões. Realizamos um planejamento para implantação e execução das atividades.

Antes de começarmos a executar os planos de ação, os professores responderam a um questionário e foram entrevistados pelo pesquisador, a fim de caracterizar o perfil de cada um. As questões eram relativas a carga horária, formação acadêmica, tempo de formação, cursos de pós-graduação e suas principais dificuldades em sala de aula.

Após a implantação do sistema aquapônico na escola, os professores foram informados de que poderiam iniciar as atividades propostas nos planos, o que ocorreu no início do segundo semestre do ano letivo de 2016. Em uma nova reunião de planejamento, estipulamos um cronograma semanal para que os professores pudessem planejar suas aulas práticas no sistema aquapônico e para não conflitar horários de uso do sistema. Assim, cada turma teria a oportunidade de visitar e utilizar o sistema, sem que outras turmas e estivessem visitando.

Como existiam um planejamento e um cronograma predeterminados, era possível ao pesquisador acompanhar as aulas dos professores, registrando áudio, vídeo, fotos e fazendo anotações em seu diário de campo. E, no final do ano letivo, após todos terem ministrado suas aulas no sistema de aquaponia, entrevistamos os professores, com o objetivo de extrair informações e inferir se o uso do sistema poderia ser empregado nas escolas como apoio didático para aulas práticas na área de ciências.

\footnotetext{
${ }^{5}$ Todas as fotografias usadas neste artigo têm o consentimento escrito dos retratados para publicação.
} 


\section{Resultados}

Os resultados estão aqui divididos em partes, para melhor entendimento pelo leitor. Inicialmente, apresentamos o perfil dos professores participantes da pesquisa e suas principais dificuldades para a utilização de atividades extraclasse em seu cotidiano. Em um segundo momento, explicitamos aos leitores as propostas de atividades práticas que utilizam o sistema aquapônico como ferramenta auxiliar para apresentação de conteúdos obrigatórios nos planos de ensino desses professores. E, por fim, expomos impressões, críticas e sugestões dos professores, referentes à utilização de projetos como facilitadores do desenvolvimento das atividades acadêmicas.

É importante ressaltar que todos os professores das disciplinas de biologia, química, matemática e física receberam um questionário ao qual foram convidados a responder; no entanto, nem todos o devolveram preenchido. Nove professores responderam, concordaram em participar e autorizaram o uso dos dados coletados para publicação (Quadro 1). Informamos a eles que, durante a comunicação da pesquisa, suas identidades seriam preservadas.

\section{Perfil dos professores}

Os resultados das entrevistas com os docentes envolvidos no projeto retratam a dificuldade de trabalho interdisciplinar e projetos integrados na escola: 7 dos 9 professores participantes relataram que possuíam outro emprego além da escola, 7 dos 9 possuem mais de 5 anos de experiência em docência, 4 são efetivos/concursados pela Secretaria de Educação do estado, 1 é contratado por 40 horas e 4 são contratados na escola para ministrar 20 horas aula. Seis dos 9 professores possuem pós-graduação na área de formação. Dentre as principais dificuldades apresentadas por eles, a falta de tempo para preparar aulas foi a principal; a indisciplina foi citada por 6 dos 9 professores; a falta de organização institucional, o excesso de atividades extraclasse, o local inadequado para atividades práticas, a falta de compromisso e pontualidade dos alunos e o desinteresse foram citados como outros fatores que dificultam a regência por parte dos professores.

Garcia (1999) descreve que a indisciplina reflete o descontentamento dos alunos e precisa ser analisada para além do rótulo de indisciplina e pensada como expressão de uma consciência social em formação. Golba (2009), por seu lado, entende que o descontentamento dos alunos se dá pelo fato de as aulas serem pouco planejadas e desinteressantes, o que pode ser entendido, se observarmos que os professores relatam não ter tempo suficiente para preparar atividades, planejar aulas e, consequentemente, desenvolvê-las. Além disso, a carência de um local para ministrar aulas práticas e realizar pesquisas, salientada pelos professores, parece também colaborar para essa insatisfação.

Lapo e Bueno (2003) acrescentam a esse rol de aspectos já elencados outros fatores, responsáveis por desmotivar os professores: sua baixa remuneração, aliada às péssimas condições de trabalho, o aparecimento de um emprego mais rentável, a falta de tempo para concluir estudos, a ausência de perspectiva de crescimento profissional e de mudanças no sistema educacional. Em nossos resultados, o fator baixa remuneração não foi relevante, porém, metade dos professores trabalha 60 horas semanais, o que reflete a baixa remuneração da profissão. Eles buscam alternativas de subsistência e manutenção familiar, o que lhes ocupa o tempo e gera a impossibilidade de preparar e planejar suas atividades. 
Os docentes relataram dificuldades para trabalhar de forma interdisciplinar, visto que os colegas não têm tempo para planejar e realizar quaisquer atividades. Também apontam que os conteúdos obrigatórios exigidos pela Secretaria de Educação do Estado do Amazonas são intermináveis. Esse fato é exposto por Klein (2001), que, em seu artigo, ressalta a dificuldade pedagógica para trabalhar de forma interdisciplinar e pondera que não se faz interdisciplinaridade sem os professores terem sido preparados para essa forma de trabalho. Já Lenoir, Rey e Fazenda (2001) entendem que a interdisciplinaridade em sala de aula deve fazer parte do projeto político-pedagógico da escola, que deverá favorecer essas atividades. Sendo assim, não basta apenas os professores desejarem realizar atividades em conjunto, mas os planos de ensino de cada disciplina deverão ser pensados em conjunto, a fim de que as disciplinas possam se aproximar cada vez mais.

No trabalho realizado por Gaspari et al. (2006), os autores relatam que, provavelmente, a falta de concentração, muitas vezes chamada de indisciplina, ocorre pelo fato de os conteúdos não serem atrativos aos alunos, pois o ensino tradicional não favorece a vontade de prestar atenção e concentrar-se nos assuntos ministrados pelos professores. Esses autores, ao entrevistar os professores, relatam que a falta de materiais impede o aproveitamento satisfatório da disciplina.

\section{Propostas de atividades utilizando o sistema aquapônico}

A segunda parte dos resultados está reservada à exposição dos planos de aula produzidos por alguns dos professores envolvidos na pesquisa utilizando a aquaponia como ferramenta didática e ao relato do que lhes foi possível executar.

Inicialmente houve resistência por parte dos professores a embarcar nesta empreitada de utilizar projetos para fins educativos. Os motivos já foram relatados, porém percebemos, na entrevista final, que eles não se motivaram a participar porque a proposta inicial de realizar o projeto não partiu deles, mas de um pesquisador externo ao contexto educacional. Os professores não tiveram a opção de escolher se iriam ou não participar: a escola recomendou que eles participassem. Avaliando os pressupostos filosóficos envolvidos em um projeto de pesquisa-ação, como a participação engajada dos participantes e a relação entre o problema e suas possíveis soluções, notamos que a participação na concepção e na elaboração do projeto e do problema foram os principais fatores relacionados à não adesão voluntária ao projeto. Mesmo com esses percalços, após o início do projeto, sua implantação e o início das atividades, a abordagem dada pelo pesquisador e seus colaboradores fizeram com que os professores se interessassem em utilizar o sistema e participar de forma efetiva na condução e na realização das propostas.

As propostas feitas pelos professores foram agrupadas por áreas, e os professores se reuniram para, juntos, pensar na execução das ações (Quadro 1). 
Quadro 1 - Propostas dos professores para a utilização do sistema aquapônico na sala de aula

\begin{tabular}{|c|c|c|}
\hline Disciplina & Proposta inicial & Proposta Apresentada \\
\hline Biologia & $\begin{array}{l}\text { Comparar a estrutura e o funcionamento dos } \\
\text { diferentes tipos de tecidos, identificando-os e } \\
\text { compreendendo sua estrutura ( } 1^{\circ} \text { ano ensino } \\
\text { médio). } \\
\text { Embriologia vegetal e animal, reprodução dos } \\
\text { seres vivos, fases dos anexos embrionários e } \\
\text { gametogênese ( } 2^{\circ} \text { ano ensino médio). }\end{array}$ & $\begin{array}{l}\text { Foi repensada uma nova proposta } \\
\text { devido à falta de tempo para preparo das } \\
\text { atividades, falta de lupas e microscópios } \\
\text { e muito conteúdo obrigatório a ser } \\
\text { apresentado durante o ano letivo. } \\
\text { Uma nova proposta pautou-se em } \\
\text { discorrer sobre hibridação dos animais } \\
\text { e vegetais. As aulas foram ministradas } \\
\text { para turmas de } 1^{\circ} \text { a } 3^{\circ} \text { ano do ensino } \\
\text { médio, em parceria com os alunos } \\
\text { bolsistas PIBID. Estes produziram um } \\
\text { material didático composto por um } \\
\text { cartaz impresso com diversas figuras e } \\
\text { apresentaram aos alunos os principais } \\
\text { benefícios de se utilizar a hibridação } \\
\text { na agricultura e zootecnia. Estas aulas } \\
\text { ocorreram entre os meses de outubro e } \\
\text { novembro de } 2016 \text {. }\end{array}$ \\
\hline Matemática & $\begin{array}{l}\text { Relacionar a matemática com o sistema } \\
\text { aquapônico, utilizando conceitos de geometria } \\
\text { plana, cálculo de área, perímetro de figuras } \\
\text { geométricas presentes no sistema, calcular o } \\
\text { volume das caixas d'água e filtros }\left(2^{\circ} \text { e } 3^{\circ} \text { anos }\right. \\
\text { ensino médio). }\end{array}$ & Não houve alteração. \\
\hline Física & $\begin{array}{l}\text { Observar trocas de calor, temperatura e } \\
\text { energia interna. Medidas de temperatura, } \\
\text { escalas termométricas relação entre as escalas e } \\
\text { escalas arbitrárias ( } 2^{\circ} \text { ano ensino médio). } \\
\text { Conceitos de dilatação térmica, área } \\
\text { superficial, óptica e empuxo; Eletricidade }\left(3^{\circ}\right. \\
\text { ano ensino médio). }\end{array}$ & Não houve alteração. \\
\hline
\end{tabular}

As aulas de biologia propostas pelos professores foram repensadas, pois, no momento da elaboração da proposta, não foi levada em conta a falta de materiais e condições para executar a atividade inicial. Aos olhos do pesquisador, a alteração da proposta inicial foi bem aceita, uma vez que os professores, juntamente com os alunos do PIBID que os acompanhavam, poderiam executar as ações. A apresentação feita pelos alunos do PIBID foi avaliada como muito positiva, uma vez que prendeu a atenção dos alunos e ainda trouxe assuntos ligados ao contexto de vida dos alunos; mostrou aos estudantes das três séries do Ensino Médio os principais cruzamentos e híbridos utilizados na produção animal; demonstrou as principais vantagens e motivos para realizar os cruzamentos; e ainda discutiu sobre o ciclo de nitrogênio, os componentes produzidos pelas excretas dos peixes e sua transformação, realizada pelas bactérias nitrificantes (Figura 2). 
Quadro 1 - Propostas dos professores para a utilização do sistema aquapônico na sala de aula

\begin{tabular}{|c|c|c|}
\hline Disciplina & Proposta inicial & Proposta Apresentada \\
\hline Química & $\begin{array}{l}\text { Ciclo dos nutrientes, função do nitrogênio, } \\
\text { fósforo e potássio para os vegetais, formas } \\
\text { de produção de amônia e nitrito dentro do } \\
\text { sistema ( } 1^{\circ} \text { ano ensino médio). } \\
\text { Conceito de poder tampão utilizando o } \\
\text { sistema e as variações do pH no decorrer dos } \\
\text { dias ( } 2^{\circ} \text { ano ensino médio). } \\
\text { Biomoléculas, principalmente a proteína e seus } \\
\text { subprodutos excretados pelos peixes }\left(3^{\circ} \text { ano }\right. \\
\text { ensino médio). }\end{array}$ & $\begin{array}{l}\text { As aulas de química para os alunos de } \\
\text { primeiro ano foram ministradas no } \\
\text { entorno do sistema aquapônico. Nesta } \\
\text { aula prática, o professor apresentou } \\
\text { o sistema aos alunos, explicou o } \\
\text { funcionamento do filtro biológico, do } \\
\text { tanque de produção de organismos } \\
\text { aquáticos e a bancada de produção } \\
\text { de hortaliças. Em seguida, utilizando } \\
\text { um kit de análise de água, o professor } \\
\text { demonstrou como se realizam } \\
\text { análises de pH e amônia pelo método } \\
\text { colorimétrico e explicou aos alunos } \\
\text { sua importância e sua influência no } \\
\text { sistema de aquaponia. Para as turmas } \\
\text { de terceiro ano as aulas foram divididas } \\
\text { em duas partes, a primeira teórica, onde } \\
\text { foram apresentados os compostos } \\
\text { derivados de uma molécula de proteína } \\
\text { e as biomoléculas orgânicas. Após essa } \\
\text { parte, os alunos foram conduzidos até } \\
\text { o sistema aquapônico, onde tiveram a } \\
\text { oportunidade de verificar na prática a } \\
\text { influência do filtro biológico no sistema } \\
\text { e realizaram análises de água, mitigando } \\
\text { os níveis de nitrito e amônia na água do } \\
\text { sistema. }\end{array}$ \\
\hline
\end{tabular}

Fonte: elaborado pelos autores.

Figura 2 - Apresentação do sistema aquapônico aos alunos do ensino médio

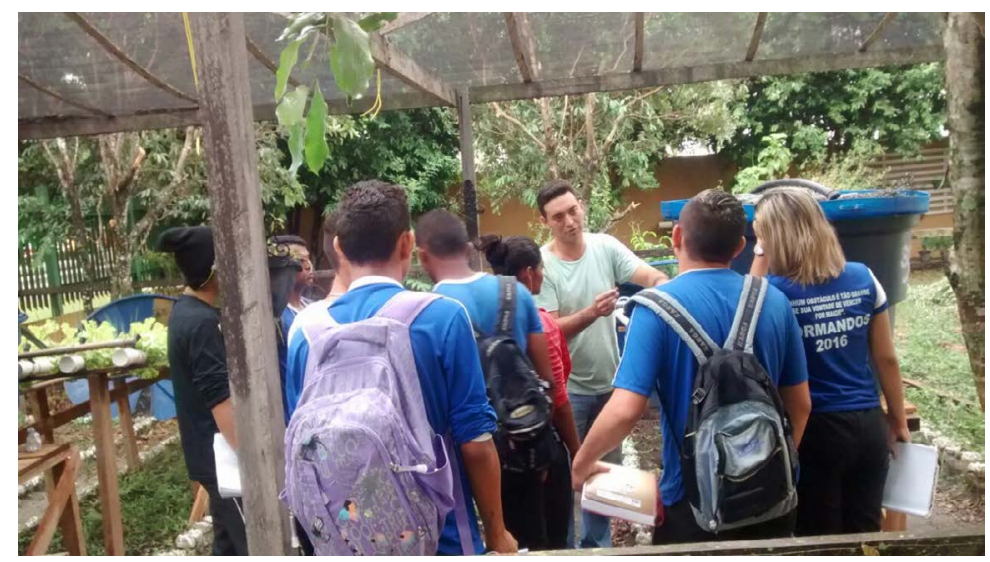

Fonte: Arquivo dos autores. 
As aulas da disciplina de matemática ocorreram de acordo com o planejado: os professores das turmas de segundos e terceiros anos conduziram os alunos até o sistema aquapônico instalado na escola e, com o auxílio de bolsistas do PIBID de matemática, apresentaram a aquaponia aos alunos e, em seguida, com auxílio de réguas e trenas, iniciaram a parte prática da aula. Alguns alunos nunca haviam tido a experiência de utilizar a trena e não tinham ideia de como se fazia para determinar a área de um determinado terreno. Avaliamos como muito proveitosa a atividade realizada, uma vez que os alunos vivenciaram o cotidiano de um sistema de produção, aliando prática e teoria em uma mesma aula.

As atividades de física foram muito dinâmicas, os professores conduziram seus alunos até o sistema aquapônico no horário de suas aulas e explicaram na prática o conceito de empuxo, utilizando uma garrafa PET e um pedaço de isopor. Para o cálculo de consumo de energia, a bomba e o compressor de ar utilizado para abastecer o sistema aquapônico foram retirados, e suas potências, anotadas. Em seguida, os alunos calcularam e verificaram o consumo mensal para cada equipamento.

Nossa percepção sobre as ações realizadas pelos professores de química baseou-se na proposta inicial e na ação executada. Segundo a proposta inicial, os professores realizariam as atividades integralmente, porém não foi possível que isso ocorresse. Para conseguirmos que os professores realizassem as atividades, tivemos que nos propor a contribuir, realizando parte das ações. Ministramos as aulas para os alunos do terceiro ano, relativas às biomoléculas orgânicas e, após a apresentação teórica, apresentamos aos alunos o sistema de produção aquapônico. $\mathrm{Na}$ oportunidade, as turmas conheceram o funcionamento do sistema e seus componentes.

\section{Percepção dos professores a respeito do projeto}

Ao final das atividades os professores foram entrevistados sobre suas percepções acerca do projeto e avaliaram positivamente a iniciativa de inserir no contexto escolar o uso de projetos para dar suporte às atividades de sala de aula. Também observaram que a aquaponia poderá ser utilizada nas disciplinas de matemática, física, química e, principalmente, biologia. Além disso, o sistema, se empregado de forma interdisciplinar, contribuirá muito para o ensino de ciências nas escolas públicas.

A proposta de implantação do sistema trouxe uma oportunidade de formação continuada aos professores da escola e gerou debates sobre o uso de projetos na educação. $\mathrm{Na}$ percepção dos professores, os alunos ficaram muito interessados durante as aulas práticas nas quais se utilizou o sistema. Os professores relataram que, nas aulas teóricas, os alunos não demonstraram pelo assunto debatido o mesmo interesse que revelaram nas aulas práticas. Isso, durante as aulas, também foi percebido pelos pesquisadores.

O principal ponto positivo analisado foi que os professores tiveram a oportunidade de discutir as ações após a apresentação da proposta. Cada um deles pôde elaborar seu plano, pensar nas propostas e apresentar suas aulas nos dias e horários definidos por eles.

A principal crítica ao projeto implantado na escola foi que os professores tinham poucas oportunidades de utilizar o sistema durante suas aulas. Este fato se deu devido aos inúmeros assuntos cobrados nas ementas das disciplinas, muitas vezes impossíveis de serem ministrados devido à restrição de carga horária e às diversas atividades extraclasse distribuídas durante o ano letivo, como dia da família, desfiles cívicos, festas escolares, entre outras. 
Outro problema relatado pelos professores envolveu a concepção do projeto, pois não tiveram a oportunidade de opinar durante a sua elaboração e foram convidados a participar de algo que não conceberam. Este fato inicialmente interferiu no andamento do processo, pois sentimos certa resistência dos professores a contribuir na execução da proposta. Isso nos deixou claro que a abertura ao diálogo na construção de propostas pedagógicas na escola deve partir do coletivo.

\section{Considerações Finais}

A tarefa de relatar sobre a formação de professores e seus impactos na relação de ensino-aprendizagem não é fácil, pois muitos fatores estão diretamente ligados ao sucesso ou insucesso dessas ações. Este estudo revelou que a carga horária dos professores está diretamente relacionada com a qualidade do ensino, pois, de acordo com o relato dos docentes, muitas ações não puderam ser executadas como planejadas.

Avaliando os resultados obtidos, concluímos que, na escola estudada, os principais problemas estão relacionados à disponibilidade de tempo por parte dos professores, uma vez que trabalham em outras escolas no contraturno. Isso refletiu no tempo de planejamento e na execução das atividades propostas, e a indisciplina ou falta de interesse dos alunos pode estar relacionada com a falta de planejamento para as atividades.

As avaliações finais dos professores após as aulas utilizando o sistema foram positivas e refletiram a importância de atividades que fogem do cotidiano da sala de aula. Essas aulas diversificadas prendem a atenção dos alunos e os motivam a interagir com os professores.

Refletindo sobre a participação dos professores, percebemos que sua não participação na elaboração ou na concepção da proposta pode ter sido determinante na adesão inicial do projeto. Projetos idealizados em grupo tendem a ser mais bem aceitos pelos grupos, refletindo as teorias da pesquisa-ação, em que as ideias são concebidas em grupo e os resultados, mais efetivos.

A parceria entre a Universidade, o Instituto Federal e a escola mostrou-se muito importante para a condução deste trabalho.

\section{Referências}

ANUÁRIO BRASILEIRO DA PESCA E AQUICULTURA 2014: 1st Brazilian Fishery and Aquaculture Yearbook 2014. Florianópolis: Associação Cultural e Educacional Brasil, 2014. Disponível em: http://formsus.datasus.gov.br/novoimgarq/16061/2489520_218117.pdf. Acesso em: 24 abr. 2019.

AUSUBEL, D. P. Aquisição e retenção de conhecimentos: uma perspectiva cognitiva. Lisboa: Paralelo, 2003.

BOLAM, R.; MCMAHON, A. Literature, definitions and model: towards a conceptual map. In: DAY, C. (ed.). International handbook on the continuing professional development of teachers. Berkshire: McGraw Hill Education, 2004. p. 33-64. 
CARVALHO, A. M. P.; GIL-PÉREZ, D. Formação de professores de ciências. São Paulo: Cortez, 1993.

DUFFY, T. M.; CUNNINGHAM, D. J. Constructivism: implications for the design and delivery of instruction. In: JONASSEN, D. H. (ed.). Handbook of research for educational communications and technology. New York: Macmillan, 1996. p. 170-98.

GARCIA, J. Indisciplina na escola: uma reflexão sobre a dimensão preventiva. Revista Paranaense de Desenvolvimento, Curitiba, n. 95, p. 101-108, 1999. Disponível em: http:// www.ipardes.pr.gov.br/ojs/index.php/revistaparanaense/article/view/275/229. Acesso em: 24 abr. 2019.

GASPARI, T. C. et al. A realidade dos professores de educação física na escola: suas dificuldades e sugestões. Revista Mineira de Educação Física, Viçosa, v. 14, n. 1, p. 109-37, 2006.

GENELLO, L. et al. Fish in the classroom: a survey of the use of aquaponics in education.

European Journal of Health \& Biology Education, Enschede, v. 4, n. 2, p. 9-20, 2015. DOI: http://dx.doi.org/10.20897/lectito.201502.

GOLBA, M. A. M. Os motivos da indisciplina na escola: a perspectiva dos alunos. In: CONGRESSO NACIONAL DE EDUCAÇÃO, 9., 2009, Curitiba. Anais [...]. Curitiba: PUC-PR, 2009. Disponível em: http://educere.bruc.com.br/arquivo/pdf2009/2071_1923. pdf. Acesso em: 25 abr. 2019.

GRANT, M. M.; HILL, J. R. Weighing the risks with the rewards: implementing studentcentered pedagogy within high-stakes testing. In: LAMBERT, R.; MCCARTHY, C. (ed.). Understanding teacher stress in an age of accountability. Greenwich: Information Age Press, 2006. p. 19-42.

HART, E. R.; WEBB, J. B.; DANYLCHUK, A. J. Implementation of aquaponics in education: an assessment of challenges and solutions. Science Education International, Izmir, v. 24, n. 4, p. 460-480, 2013. Disponível em: https://files.eric.ed.gov/fulltext/ EJ1022306.pdf. Acesso em: 30 ago. 2016.

HERTZOG, N. B. Transporting pedagogy: implementing the project approach in two firstgrade classrooms. Journal of Advanced Academics, Thousand Oaks, v. 18, n. 4, p. 530-64, 2007. DOI: https://doi.org/10.4219/jaa-2007-559.

KAPP, E. Improving student teamwork in a collaborative project-based course. College Teaching, London, v. 57, n. 3, p. 139-43, 2009. DOI: https://doi.org/10.3200/ СТCH.57.3.139-143.

KLEIN, J. T. Ensino interdisciplinar: didática e teoria. In: FAZENDA, I. C. A. (org.). Didática e interdisciplinaridade. 6. ed. Campinas: Papirus, 2001. p. 109-132.

KOLODNER, J. L. et al. Problem-based learning meets case-based reasoning in the middleschool science classroom: putting learning by design(tm) into practice. The Journal of the Learning Sciences, Philadelphia, v. 12, n. 4, p. 495-547, 2003. DOI: https://doi. org/10.1207/S15327809JLS1204_2. 
Souza, R. T. Y. B.; Souza, L. O.; Oliveira, S. R.; Takahashi, E. L. H.

LAPO, F. R.; BUENO, B. O. Professores, desencanto com a profissão e abandono do magistério. Cadernos de Pesquisa, São Paulo, n. 118, p. 65-88, mar. 2003. DOI: https:// doi.org/10.1590/S0100-15742003000100004.

LENOIR, Y.; REY, B.; FAZENDA, I. Les fondements de l'interdisciplinarité dans la formation à l'enseignement. Sherbrooke, Québec: Éditions du CRP, 2001.

MENEZES, L. C. (org.). Formação continuada de professores de ciências no contexto ibero-americano. Campinas: Autores Associados; São Paulo: NUPES, 1996.

MEYER, D. K.; TURNER, J. C.; SPENCER, C. A. Challenge in a mathematics classroom: students' motivation and strategies in PBL. The Elementary School Journal, Chicago, v. 97 , n. 5, p. 501-21, 1997.

NÓVOA, A. A formação contínua entre a pessoa-professor e a organização-escola.

Inovação, Porto, v. 4, n. 1, p. 63-76, 1991.

PARMER, S. M. et al. School gardens: an experiential learning approach for a nutrition education program to increase fruit and vegetable knowledge, preference, and consumption among second-grade students. Journal of Nutrition Education and Behavior, New York, v. 41, n. 3, p. 212-217, 2009. DOI: https://doi.org/10.1016/j.jneb.2008.06.002.

SANTOS, M. T. Iniciativas de desenvolvimento sustentável das comunidades do Rio Amazonas / Solimões. Manaus: ProVárzea: Ibama, 2004.

SHULMAN, L. S. Those who understand: knowledge growth in teaching. Educational Researcher, Thousand Oaks, v. 15, n. 2, p. 4-14, 1987. DOI: https://doi. org/10.3102/0013189X015002004.

SOUZA, N. C.; MANCINI, G. C. O uso de recursos da internet na capacitação de professores. In: ENCONTRO PERSPECTIVAS DO ENSINO DE BIOLOGIA, 8., 2002, São Paulo. Anais [...]. São Paulo: FEUSP, 2002. 1 CD-ROM.

TEIXEIRA, P. M. M. Reflexões sobre o ensino de biologia realizado em nossas escolas. In: ENCONTRO NACIONAL DE PESQUISA EM EDUCAÇÃO EM CIÊNCIAS, 3., 2001, Atibaia. Anais [...]. São Paulo: ABRAPEC, 2001. 1 CD-ROM.

TERIGI, F. Desarrollo profesional continuo y carrera docente en América Latina. Santiago: PREAL, 2010. (Documentos, 50).

WARDLOW, G. et al. Enhancing student interest in the agricultural sciences through aquaponics. Journal of Natural Resources and Life Science Education, Madison, v. 31, p. 55-58, 2002.

WILLIAMS, D. R.; DIXON, P. S. Impact of garden-based learning on academic outcomes in schools: synthesis of research between 1990 and 2010. Review of Educational Research, Thousand Oaks, v. 83, n. 2, p. 211-235, 2013.

Artigo recebido em 21/12/2017. Aceito em 17/11/2018.

Contato: Instituto Federal de Educação, Ciência e Tecnologia do

Amazonas, Itacoatiara, 69101-242, AM, Amazonas, Brasil. 